\title{
REVIEW
}

\section{Brain death and marginal grafts in liver transplantation}

\author{
MB Jiménez-Castro ${ }^{1}$, J Gracia-Sancho ${ }^{2}$ and C Peralta ${ }^{*, 1}$
}

It is well known that most organs for transplantation are currently procured from brain-dead donors; however, the presence of brain death is an important risk factor in liver transplantation. In addition, one of the mechanisms to avoid the shortage of liver grafts for transplant is the use of marginal livers, which may show higher risk of primary non-function or initial poor function. To our knowledge, very few reviews have focused in the field of liver transplantation using brain-dead donors; moreover, reviews that focused on both brain death and marginal grafts in liver transplantation, both being key risk factors in clinical practice, have not been published elsewhere. The present review aims to describe the recent findings and the state-of-the-art knowledge regarding the pathophysiological changes occurring during brain death, their effects on marginal liver grafts and summarize the more controversial topics of this pathology. We also review the therapeutic strategies designed to date to reduce the detrimental effects of brain death in both marginal and optimal livers, attempting to explain why such strategies have not solved the clinical problem of liver transplantation.

Cell Death and Disease (2015) 6, e1777; doi:10.1038/cddis.2015.147; published online 4 June 2015

Facts

- Brain death $(\mathrm{BD})$ and marginal grafts are both key risk factors in clinical liver transplantation (LT).

- There is a significant disparity in results regarding the changes induced by $\mathrm{BD}$ as well as the use of marginal livers, and their relevance in LT.

- The strategies applied in LT have been mainly focused in the treatment with different hormones to stabilize the hemodynamic disorders associated with $\mathrm{BD}$, whereas the strategies focused at protecting liver grafts are performed in non-BD surgical conditions.

\section{Open Questions}

- Future prospective, randomized clinical studies and studies that include a sufficient number of marginal donors will be required to elucidate the effects of $\mathrm{BD}$ on marginal liver grafts, and to select the most appropriate marginal organs for transplant.

- Future research in experimental models of LT using $\mathrm{BD}$ donors is strongly required to understand the pathophysiology of $\mathrm{BD}$, and, therefore, elucidate the consequences of $\mathrm{BD}$.

- The experimental conditions focused not only on liver graft damage associated with transplantation but also on brain-dead donor, and should maximally mimic the clinical situation of LT to ultimately develop effective therapeutic strategies in this setting.

\section{Deceased Donation}

Deceased donation includes two types of donation: donation after circulatory death (DCD) and donation after brain death (DBD). The fundamental distinction between DCD and DBD is the diagnosis of death. DCD describes the retrieval of organs for the purpose of transplantation, which follows death confirmed using circulatory criteria, and contrasts with the standard model for deceased donation, namely donation after the confirmation of death using neurological criteria ${ }^{1,2}$ (Figure 1). The potential contribution of DCD to overall deceased donor numbers varies internationally and comprises between 4 and $20 \%$ of transplanted grafts among centers with high rates of use. ${ }^{3}$

$\mathrm{BD}$ has been defined as the irreversible loss of brain and brain stem function, usually caused by major hemorrhage, hypoxia or metabolic dysregulation. ${ }^{4}$ The diagnosis is based on a comprehensive neurologic assessment with the absence of brain stem reflexes and apnea. Electroencephalography, transcranial Duplex-ultrasound or cerebral angiography is required in cases of clinical examination uncertainty. ${ }^{5}$ The DBD is always ventilated before death and the heart remains beating at the time of retrieval, thus virtually eliminating any warm ischemic injury to donor organs.

\footnotetext{
${ }^{1}$ Centro de Investigación Biomédica en Red de Enfermedades Hepáticas y Digestivas, Institut d'Investigacions Biomèdiques August Pi i Sunyer IDIBAPS, Esther Koplowitz Center, Barcelona, Spain and ${ }^{2}$ Barcelona Hepatic Hemodynamic Laboratory, IDIBAPS, CIBEREHD, Barcelona, Spain

*Corresponding author: C Peralta, Centro de Investigación Biomédica en Red de Enfermedades Hepáticas y Digestivas, Institut d’Investigacions Biomèdiques August Pi i Sunyer, Esther Koplowitz Center, Roselló 149-153, 3rd Floor, Office 3.8, 08036 Barcelona, Spain. Tel: +34 932275400 ext 4177 ; Fax: +34 93 3129406; E-mail: cperalta@clinic.ub.es

Abbreviations: $\mathrm{ACH}$, acetylcholine; $\mathrm{BD}$, brain death; $\mathrm{DBD}$, donation after brain death; $\mathrm{DCD}$, donation after circulatory death; $\mathrm{HCV}$, hepatitis $\mathrm{C}$ virus; ICP, intracranial pressure; $\mathrm{PC}$, ischemic preconditioning; LT, liver transplantation

Received 20.2.15; revised 23.2.15; accepted 04.5.15; Edited by G Melino
} 


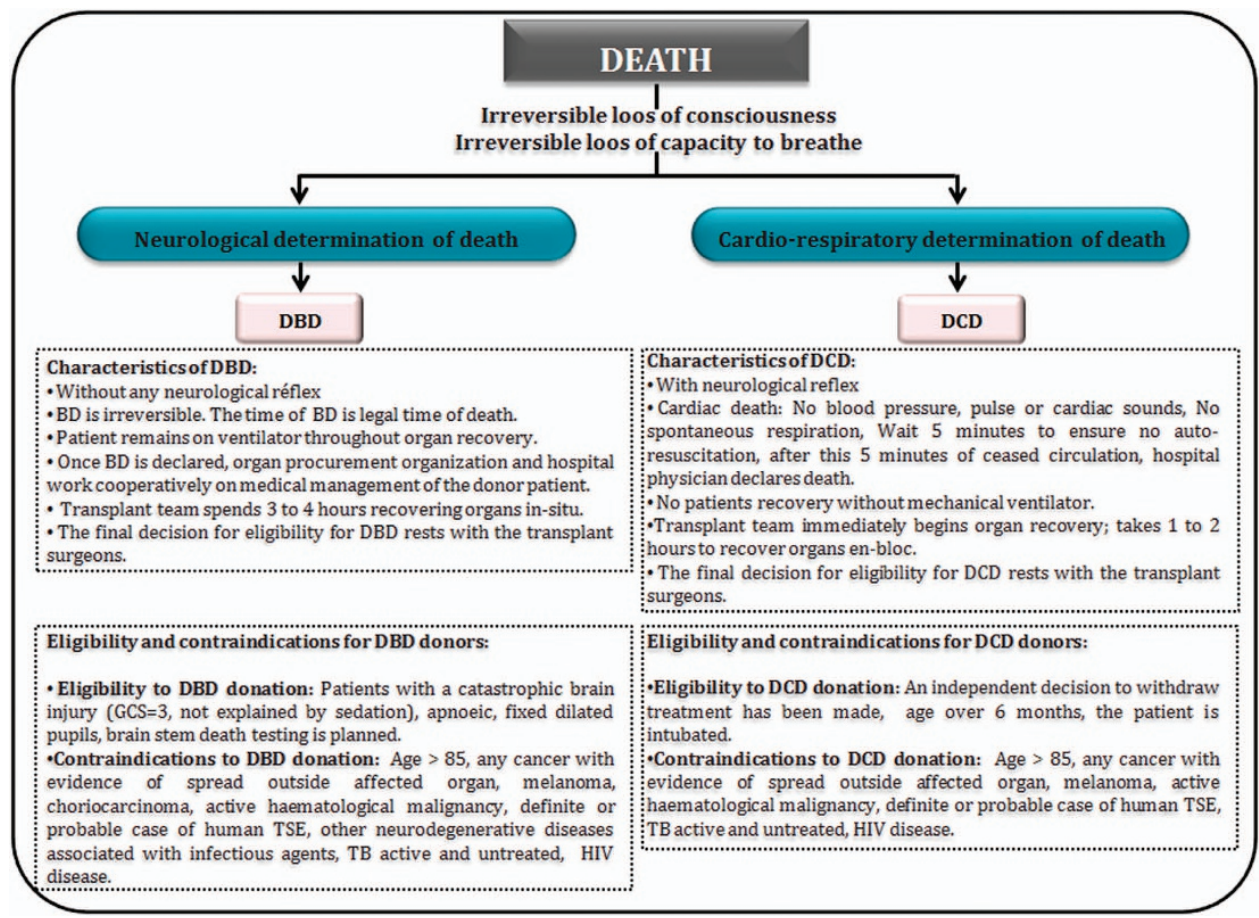

Figure 1 Comparison of DBDs and DCDs. Characteristics, eligibility and contraindications from DBD and DCD donors. GCS, Glasgow Coma Scale; HIV, human immunodeficiency virus; TB, tuberculosis; TSE, transmissible spongiform encephalopathy

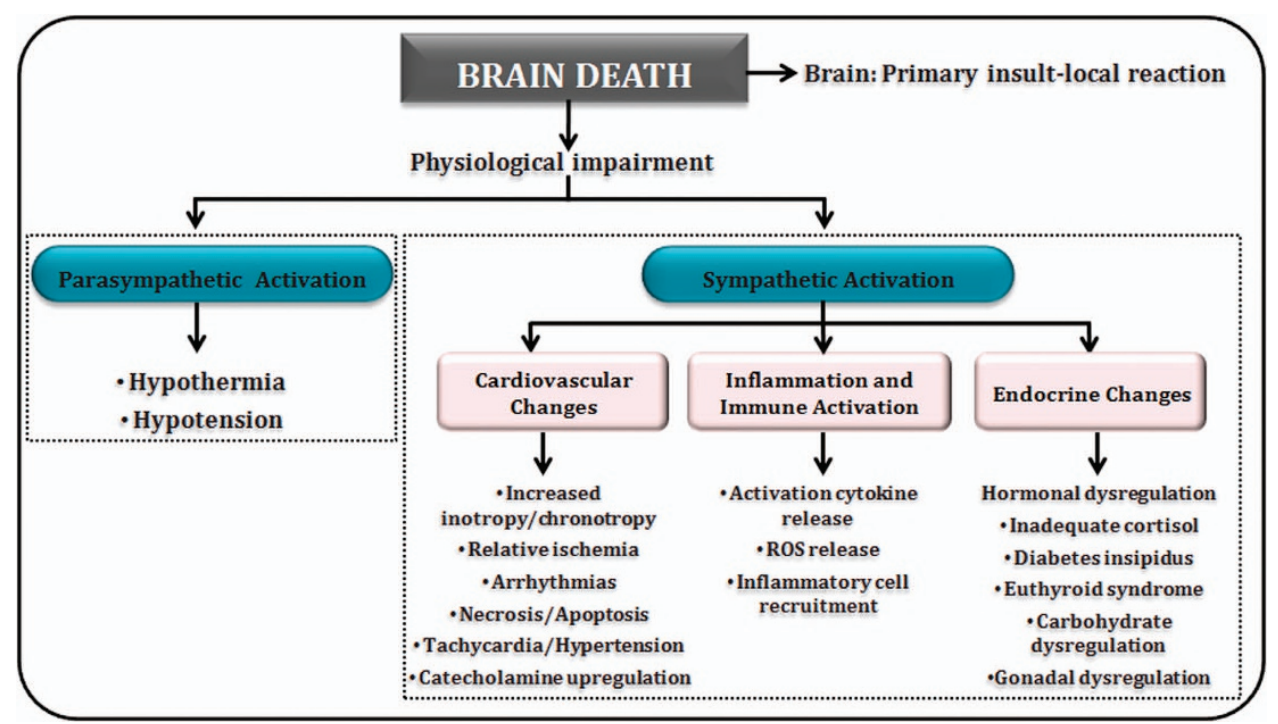

Figure 2 Pathophysiological changes occurring during and after BD. It begins with physiological impairment and consequently an alteration in sympathetic and parasympathetic branches. In the first, cardiovascular and endocrine changes and inflammation and immune activation are the most representative changes

\section{Pathophysiological Changes Occurring During and After BD}

$\mathrm{BD}$ is the terminal phase of a sequence of events frequently commencing with cerebral trauma or cerebrovascular hemorrhage. When the patient is declared brain dead, this chain of events has already affected all potential donor organs. Systemic and hormonal changes arise immediately when intracranial pressure (ICP) increases. Hemodynamic events, hormonal changes and inflammation and immune activation occur consequently to BD. ${ }^{1,6}$ Figure 2 summarizes some of the pathophysiological events occurring during and after BD. However, it should be considered that there is a range of different results with regard to the changes induced by BD and their relevance in LT. Such differences may explain why the detrimental effects of $\mathrm{BD}$ in $\mathrm{LT}$ remain as an unresolved problem in the clinical practice.

It has been reported that in clinical situations, as a result of $\mathrm{BD}$, massive catecholamine is systemically released, which 
causes an increase in heart rate and leads to vasoconstriction with increments in vascular resistance and blood pressure. Later, a decline in serum catecholamine levels and peripheral vascular resistance is observed, which finally results into a cardiovascular collapse owing to hypovolemia. ${ }^{7,8}$ In face of deteriorating hemodynamics, a compromised abdominal organ perfusion and reduced oxygenation is becoming evident. $^{9}$ Accordingly, a shift from aerobic to anaerobic metabolism and acidosis is registered, clinically reflected by elevated serum levels of lactate and free fatty acids, and further promoted by decreased insulin secretion and hyperglycemia., ${ }^{9,10}$ Activation of proinflammatory signaling pathways is finally observed. ${ }^{9,11-15}$

On the other hand, it should be considered that both the magnitude of the catecholamine response and the extent of the myocardial injury seem to be correlated to the velocity of increase in ICP. Indeed, in experimental models of BD, an explosive increase in ICP resulted in increased plasma catecholamine, accompanied by extensive heart ischemic injury within $1 \mathrm{~h}$ after BD. However, a gradual increase in ICP, inducing $B D$ after $2.5 \mathrm{~h}$, resulted in lower increases in plasma catecholamine levels, and only mild heart ischemic injury. ${ }^{16}$ Consequently, from our point of view, further experimental studies are required to elucidate the relevance of the different magnitude of the catecholamine released consequently to BD on liver grafts undergoing transplantation. This would probably induce different inflammation and damage degree and differential underlying pathophysiological mechanisms in liver grafts undergoing transplantation. Thus, under these clinical situations, different protective treatments might be required to reduce the detrimental effects of $B D$ in $L T$.

In the same line, different results related to the hormonal changes due to anterior and posterior pituitary failure have been described. ${ }^{12,17-21}$ Indeed, it has been reported that anterior pituitary function seems to be well preserved in most donors with normal values of thyroid-stimulating hormone, adrenocorticotropic hormone and human growth hormone. Other authors described that, following BD, the function of the pituitary gland can remain active to a variable degree. However, other results indicate that when ICP exceeds the mean arterial pressure, brain perfusion stops, the pituitary gland is damaged and its hormone secretion ceases. Considering the aforementioned data, it would be of clinical interest to assess how the damage degree in pituitary gland may induce variability in the baseline values of plasma hormone and in the pattern of reacting hormones to overall reduce the deleterious effects of $B D$ in $L T$. In addition, further experimental studies will be required to elucidate whether the variability in these hormonal changes predominantly depends on the length of time between the appearance of the noxious cause and surgery, or might be due to the etiology of BD.

\section{Strategies for Reducing BD Consequences in LT}

In a prospective randomized trial with 100 BD donors, Kotsch et al. ${ }^{22}$ reported positive outcomes in LT after administration of steroids such as methylprednisolone owing to a downregulation in proinflammatory cytokines and reduced incidence of acute rejection. In contrast, another study in $90 \mathrm{BD}$ patients failed to identify a benefit of methylprednisolone administration. ${ }^{23}$ Despite the heterogeneity of outcomes in clinical trials, steroid administration has been incorporated into donor management protocols, ${ }^{24-27}$ and the regimen most frequently used for steroid treatment involves large doses of methylprednisolone. However, there is concern that high doses of steroids may worsen hyperglycemia, which may itself be detrimental to organ function ${ }^{28}$ (Table 1). In line with this, in an experimental study by Rebolledo et al., ${ }^{29}$ the administration of prednisolone had different and disparent effects on liver allografts. Overall, there is a clear need to establish the effects of steroid treatment on liver grafts. Moreover, no conclusive data regarding this topic in marginal livers has been published.

Different results have been reported regarding the treatment with catecholamines. An experimental study indicated that the combined administration of epinephrine and vasopressin had a synergistic effect in improving the hemodynamics and maintenance of energy status of the liver. In a study based on 755 liver transplants performed in 26 hepatic transplantation centers, donor treatment with catecholamines (dopamine, epinefrine and norepinefrine) (separately or in combination) had little benefits on LT outcomes, ${ }^{30}$ whereas other paper including 12 LT reported adverse outcome following catecholamines treatment. ${ }^{31}$ The proinflammatory effects of norepinephrine increasing CXCL1 and IL-1 and the detrimental effects of dopamine impairing liver metabolism by reducing the redox state of liver mitochondria observed in experimental BD conditions $^{32,33}$ may explain the negative effects of catecholamines in LT (Table 1).

Different reports have also been published on the relevance of hormonal changes consequently to BD. For instance, thyroid hormone replacement therapy is a controversial part of donor management. In fact, experimental studies in BD organ donors by Novitzky et al. ${ }^{10}$ indicated that T3 treatment reduced lactate and free fatty acids in plasma, suggesting improvements in metabolic status. ${ }^{34}$ However, in a review by Powner and Hernandez, ${ }^{35}$ based on meta-analysis studies of more than 1000 patients, it was concluded that routine replacement of thyroid hormones for all donors could not be advocated (Table 1).

Given all these data into account, the strategies applied in LT have been mainly focused in the treatment with different hormones to stabilize the hemodynamic disorders associated with $\mathrm{BD}$, whereas their effects on liver graft function and viability remain to be elucidated. In addition, different results have been found when comparing clinical studies, and comparing the few experimental studies reported with the clinical studies. Future experimental and clinical investigations will be required to optimize the management of BD organs to provide a hemodynamic stability during BD without adverse side effects for liver grafts and recipients. Moreover, it should be considered that a large number of factors and mediators also have a role in the mechanisms responsible for the detrimental effects of $\mathrm{BD}$ in $\mathrm{LT}$; thus, strategies focused exclusively in providing hemodynamic stability during BD may be insufficient to prevent the deleterious effects of BD in LT. 


\section{Marginal Livers from Brain Dead Donors for Transplantation}

There are two categories of marginal livers, ${ }^{36}$ (A) livers that carry a high risk of technical complications and impaired function (i.e. elderly donors, steatotic donors or split livers) and (B) grafts that carry a risk of transmission of infection or malignancy to the recipient (i.e. donor with viral infections or donors with malignancy).

Despite numerous retrospective studies, the impact of each donor variables on graft function and recipient survival is still under investigation because of the contradictory results. Some investigators have indicated comparable results regarding graft function and patient survival after transplantation of marginal donors versus standard grafts, but most reports support a clear correlation between graft quality and posttransplant outcome. ${ }^{37,38}$ Actually, the use and acceptance of marginal livers varies between different transplant centers ${ }^{39}$ and depends on the judgment of the transplant surgeon. Thus, retrieval teams may be cautious when accepting marginal organs for transplantation.

Multiple methods are currently being investigated to minimize the effects of ischemia-reperfusion (I/R) injury to allow the use of marginal organs, including anti-inflammatory approaches to attenuate cytokines, blockade of adhesion molecules, antiapoptotic strategies, among others. However, these studies are performed in non-BD surgical conditions and have been focused manly in steatotic or aged livers. Only a recent study, as described below, describes a potential treatment in both steatotic and non-steatotic liver grafts undergoing LT from cadaveric donors.

Marginal livers with high risk of technical complications and impaired function. Donor age steadily increased over recent decades. In 1994, only $20 \%$ of deceased donors were 50 years or older. This percentage increased by $>150 \%$ in the year $2004 .{ }^{40}$ Although initial studies suggested that donors $>50$ years old (without additional risk factors) have similar outcomes compared with younger donors, ${ }^{41,42}$ and therefore age should not be a contraindication to liver donation, later reports concluded the contrary. Indeed, Busquets et al. ${ }^{43}$ reported that liver grafts from donors $>70$ years old had a higher risk for long-term graft failure and mortality, and more recent studies using large databases and different registries clearly identified donor age as an important risk factor related to graft failure and patient mortality. ${ }^{44}$

The few experimental studies of LT performed with old donors have been performed in non-BD surgical conditions. In such studies, it has been shown that livers from aged donors are more susceptible to endothelial cell injury and show impaired energy metabolism and reduced blood flow compared with younger livers. ${ }^{45,46}$ Future studies will be required to evaluate the influence of these two factors, aging and BD, separately or in combination, in experimental models of $\mathrm{LT}$, and therefore elucidate how BD may affect these liver grafts. Indeed, considering that the mechanisms responsible for $\mathrm{I} / \mathrm{R}$ damage might be different (or more exacerbated) in older livers, different drugs or different drug doses should be 
administered in both young and old livers to protect them effectively against the detrimental effects of BD.

Regarding steatotic liver grafts, it has been reported that an estimated $20 \%$ of persons who accidentally die suffer from a mild or moderate grade of liver steatosis. ${ }^{47-49}$ Given the prevalence of hepatic steatosis in the society, this represents a large potential pool of donors. However, the clinical problem is still unresolved as steatotic livers are more susceptible to I/R injury and, when used, have poorer outcome than nonsteatotic livers. ${ }^{47,50-52}$ Indeed, LT outcome depends on the degree and type of hepatic steatosis; ${ }^{53,54}$ however, in the transplant setting, a method for determining and measurement, the extent of steatosis remains imprecise and inconsistently reported, ${ }^{55,56}$ and thus additional surrogate markers of organ quality are needed.

Experimental studies in steatotic livers have mainly focused on aggravated I/R injury after transplantation without considering $\mathrm{BD}$, even though in clinical practice around $80 \%$ of grafts are taken from brain-dead donors. In such studies, lower antioxidant capacity, higher levels of cytokine release, Kupffer cell activation and leukocyte recruitment and a compromised microcirculation were observed in steatotic liver grafts undergoing transplantation compared with non-steatotic ones. ${ }^{57,58}$ Only two studies in control animals, without transplantation, have evaluated the effects of BD in steatotic livers. In these studies, during BD-induced hypotension, portal venous and hepatic microvascular blood flow were reduced in steatotic livers compared with non-steatotic ones. ${ }^{59}$ In our opinion, as we will explain below, studies aimed at evaluating the pathophysiology of I/R associated with LT and establishing potential protective strategies in different types of livers should be performed in the presence of $\mathrm{BD}$. Indeed, a recent experimental study from our group indicated that the injurious effects of BD were more exacerbated in the presence of moderate steatosis and occurred before liver grafts were retrieved from donors. In addition, the mechanisms responsible for the detrimental effects of BD were different depending of the type of the liver, which would interfere with protective pharmacological or surgical strategies applied in liver grafts, avoiding its potential benefits. In such a study, ${ }^{60} \mathrm{BD}$ induced dysfunction in the cholinergic anti-inflammatory pathway and prevented the benefits induced by ischemic preconditioning (PC), a surgical strategy that shows benefits when it is applied in non-BD clinical situations such as hepatectomies. In fact, the study indicated that the combination of acetylcholine $(\mathrm{ACH})$ and $\mathrm{PC}$ could be considered as a feasible and easy-toperform intervention to reduce the adverse effects of BD and improve the quality of liver grafts. This specific strategy reduced the postoperative complications and increased the survival of recipients from steatotic and non-steatotic liver grafts from cadaveric donors. The advantages of combining a pharmacological and surgical strategy $(\mathrm{ACH}+\mathrm{PC})$, over a pharmacological strategy alone $(\mathrm{ACH})$, might derive from the fact that $P C$ involves a substantial number of molecular pathways that promote cellular resistance to stress, which is not observed when using a pharmacological treatment alone. ${ }^{60}$ Future studies are required to investigate whether the results obtained in an experimental model of esteatosis induced by obesity may also be extrapolated to other experimental models of liver esteatosis; as in clinical practice, the causes of hepatic steatosis are varied and include obesity, aging, moderate alcoholism, diabetes mellitus, hyperlipidemia and postmortem nutritional changes.

The use of split livers in transplant may be an option to expand the donor pool in cadaveric donors and it is possible in about $15 \%$ of optimal deceased donors. ${ }^{61}$ However, different clinical results have been reported when split livers are used for transplant. ${ }^{62-64}$ In a small series of split LT, 10 out of 12 adults receiving small grafts showed correct liver function posttransplantation. ${ }^{62}$ However, high rates of hepatic artery thrombosis, primary non-function and biliary complications, as well as problems associated with small-for-size syndrome, have been extensively reported. ${ }^{64-66}$ In our opinion, the detrimental effects of I/R injury on liver regeneration may be more exacerbated in the presence of BD. Our hypothesis is based on the following observations: split LT have a high risk of small-for-size syndrome, ${ }^{64}$ as the liver mass is not sufficient to meet the metabolic demands for the individual; in addition, I/R inherent to $L T$ negatively affects regenerative responses and BD further detriments I/R process in LT. Evidently, future investigations on this topic aimed to establish protective strategies in this type of LT are still necessary.

\section{Marginal liver grafts with risk of transmission of infection} or malignancy to the recipient. Whereas there are reasonable doubts about the use of split livers, grafts from old donors or with steatosis, there are still more questions to decide whether or not liver grafts form donors with viral infections or malignancies should be used for transplantation. In the specific scenario of hepatitis $\mathrm{C}$ virus (HCV) infection, and obviating the upcoming novel results using the newly developed therapeutic regimens, a relatively frequent retransmission of HCV to the recipient after LT, with concomitant morbidity and mortality, has been described. ${ }^{67}$ Similarly, the transmission of other donor-derived malignancies with detrimental outcomes has also been reported. ${ }^{68-70}$ Thus, it is left to the judgment of the transplanting team to determine the use of these organs under certain circumstances.

Up to now, one of the most controversial issues regarding extended-criteria donors resolves around the potential positive impact of HCV-infected donors on short-term outcomes. Donor seropositivity for HCV has been considered a contraindication for LT and not commonly practiced. However, it has been reported that 1-year patient survival rates of $97 \%$ in recipients of HCV-infected livers compared with rates of $87 \%$ for recipients of organs meeting the United Network for Organ Sharing-approved criteria, with no differences in surgical conditions including warm and cold ischemia times between both groups. ${ }^{71}$ If the results of this study are validated by others, it might have an important clinical implication because such organs are underused but overpresented in the donor pool. Again, the new panorama after the administration of the new generation of anti-HCV therapies might very much change the future in this field, requiring subsequent analysis and characterizations.

\section{Future Perspectives and Conclusions}

Most organs for transplantation originate from brain-dead donors. Although the detrimental consequences of BD have 


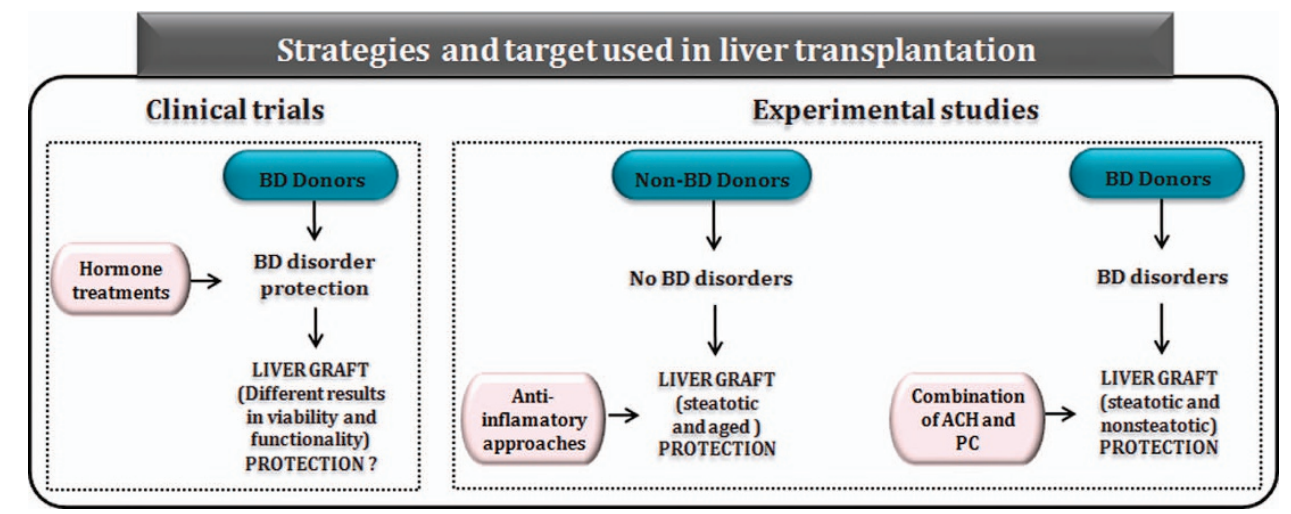

Figure 3 Therapeutic strategies evaluated in clinical and experimental models of LT. Bedside (left), different hormone treatments targeting hemodynamic deterioration owing to $\mathrm{BD}$ have shown diverse results. Benchside (right), majority of the experimental studies evaluated therapeutic strategies to protect livers undergoing I/R injury without the presence of $\mathrm{BD}$. Contrarily, a strategy based on the combination of $\mathrm{ACH}$ and $\mathrm{PC}$ revealed marked protection in the presence of $\mathrm{BD}$

been clinically described, the underlying mechanisms and their relevance in LT remain poorly understood. Indeed, few studies have evaluated the effect of BD on LT, and most of the experimental studies focused in establishing surgical or pharmacological strategies to reduce liver graft damage associated with transplantation have been performed in the absence of BD. Moreover, as stated along this review, different results on treatments, mainly focused on hemodynamic stabilization, have also been reported. On the other hand, owing to the persistent shortage of liver grafts for transplant, the use of marginal livers has been increased in the past years. However, clinical studies in LT are mainly descriptive and dissimilar results regarding the postoperative outcomes of LT when marginal livers are used have been reported. Multiple methods, in non-BD conditions, are currently being investigated to minimize the effects of I/R injury to allow the use of marginal livers for transplant. However, given the result from our recent study in steatotic and non-steatotic LT from cadaveric and non-cadaveric donors, we believe that the experimental conditions should maximally mimic the clinical situation of LT to develop ultimately effective therapeutic strategies in this setting. Such investigations should be focused not only on liver graft damage associated with transplantation but also on brain-dead donor, which may very much contribute to this pathology (Figure 3).

Future prospective, randomized clinical studies and studies that include a sufficient number of marginal donors will be required to elucidate the effect of $\mathrm{BD}$ on marginal liver grafts and to select the most appropriate marginal organs for transplant. Future research in experimental models of LT using $\mathrm{BD}$ donors is required to understand the pathophysiology of BD and elucidate the consequences of BD. These new studies should analyze the type and extent of brain injury using different times of cold ischemia and include the subanalysis of the impact of possible diseases present in the liver, with the ultimate goal to define novel and effective treatment targets. We recognize that a main difficulty when using marginal livers is to define the criteria that can be extended, because these criteria vary between centers and regions, but it is clear that different postoperative outcomes exist when marginal livers are used. Thus, further experimental research is also needed to identify better tests for evaluating the quality of donor organs. Obviously, all of this requires necessary additional efforts of multidisciplinary research groups.

\section{Conflict of Interest}

The authors declare no conflict of interest.

Acknowledgements. This research was supported by the Ministry of Economy and Competitiveness (project grant SAF2012-31238 to CP and FIS14/00029 to JG-S) Madrid, Spain and European Union (Fondos FEDER, 'una manera de hacer Europa'). MBJ-C is in receipt of a fellowship from the Sociedad Catalana de Transplantament (SCT Foundation), Barcelona, Spain. JG-S has a contract from the programa Ramón y Cajal-Ministerio de Economia y Competitividad, Madrid, Spain. CIBEREHD is funded by the Instituto de Salud Carlos III.

1. Manara AR, Murphy PG, O'Callaghan G. Donation after circulatory death. Br J Anaesth 2012; 108: i108-i121.

2. Morrissey PE, Monaco AP. Donation after circulatory death: current practices, ongoing challenges, and potential improvements. Transplantation 2014; 97 : 258-264.

3. Reddy S, Zilvetti M, Brockmann J, McLaren A, Friend P. Liver transplantation from non-heart-beating donors: current status and future prospects. Liver Transplant 2004; 10: 1223-1232.

4. Wijdicks EF, Varelas PN, Gronseth GS, Greer DM. American Academy of Neurology. Evidence-based guideline update: determining brain death in adults: report of the quality standards subcommittee of the American Academy of Neurology. Neurology 2010; 74: 1911-1918.

5. Floerchinger B, Oberhuber R, Tullius SG. Effects of brain death on organ quality and transplant outcome. Transplant Rev 2012; 26: 54-59.

6. Dziodzio T, Biebl M, Pratschke J. Impact of brain death on ischemia/reperfusion injury in liver transplantation. Curr Opin Organ Transplant 2014; 19: 108-114.

7. Powner DJ, Boccalandro C, Alp MS, Vollmer DG. Endocrine failure after traumatic brain injury in adults. Neurocrit Care 2006; 5: 61-70.

8. Perez Lopez S, Otero Hernandez J, Vazquez Moreno N, Escudero Augusto D, Alvarez Menéndez F, Astudillo González A. Brain death effects on catecholamine levels and subsequent cardiac damage assessed in organ donors. J Heart Lung Transplant 2009; 28: 815-820.

9. Herijgers $\mathrm{P}$, Leunens V, Tjandra-Maga TB, Mubagwa K, Flameng W. Changes in organ perfusion after brain death in the rat and its relation to circulating catecholamines. Transplantation 1996; 62: 330-335.

10. Novitzky D, Cooper DK, Morrell D, Isaacs S. Change from aerobic to anaerobic metabolism after brain death, and reversal following triiodothyronine therapy. Transplantation 1988; 45 : 32-36.

11. Pratschke J, Neuhaus $P$, Tullius $S G$. What can be learned from brain-death models? Transpl Int 2005; 18: 15-21.

12. Mertes PM, el Abassi K, Jaboin $Y$, Burtin $P$, Pinelli G, Carteaux JP, et al. Changes in hemodynamic and metabolic parameters following induced brain death in the pig. Transplantation 1994; 58: 414-418.

13. Baldwin AS. The NF-kappa B and I kappa B proteins: new discoveries and insights. Annu Rev Immunol 1996; 14: 649-683. 
14. Tesfamariam B, DeFelice AF. Endothelial injury in the initiation and progression of vascula disorders. Vasc Pharmacol 2007; 46: 229-237.

15. Ott L, McClain CJ, Gillespie M, Young B. Cytokines and metabolic dysfunction after severe head injury. J Neurotrauma 1994; 11: 447-472.

16. Shivalkar B, Van Loon J, Wieland W, Tjandra-Maga TB, Borgers M, Plets C, et al. Variable effects of explosive or gradual increase of intracranial pressure on myocardial structure and function. Circulation 1993; 87: 230-239.

17. Novitzky D, Wicomb WN, Cooper DKC. Electrocardiographic, hemodynamic and endocrine changes occurring during experimental brain death in the Chacma baboon. J Heart Transplant 1984; 4: 63-69.

18. Roelsgaard K, Botker HE, Stodkilde-Jorgensen H, Andreasen F, Jensen SL, Keiding S. Effects of brain death and glucose infusion on hepatic glycogen and blood hormones in the pig. Hepatology 1996; 24: 871-875.

19. Powner DJ, Hendrich A, Lagler RG, Ng RH, Madden RL. Hormonal changes in brain dead patients. Crit Care Med 1990; 18: 702-708.

20. Howlett TA, Keogh AM, Perry L, Touzel R, Rees LH. Anterior and posterior pituitary function in brain-stemdead donors. A possible role for hormonal replacement therapy. Transplantation 1989; 47: 828-834

21. Lopau K, Mark J, Schramm L, Heidbreder E, Wanner C. Hormonal changes in brain death and immune activation in the donor. Transpl Int 2000; 13: S282-S285.

22. Kotsch K, Ulrich F, Reutzel-Selke A, Pascher A, Faber W, Warnick P, et al. Methylprednisolone therapy in deceased donors reduces inflammation in the donor liver and improves outcome after liver transplantation: a prospective randomized controlled trial. Ann Surg 2008; 248: 1042-1050.

23. Amatschek S, Wilflingseder J, Pones M, Kainz A, Bodingbauer M, Mühlbacher F, et al. The effect of steroid pretreatment of deceased organ donors on liver allograft function: a blinded randomized placebo-controlled trial. J Hepatol 2012; 56: 1305-1309.

24. Novitzky D, Cooper DK, Rosendale JD, Kauffman HM. Hormonal therapy of the brain-dead organ donor: experimental and clinical studies. Transplantation 2006; 82 1396-1401.

25. Novitzky D, Wicomb WN, Cooper DK, Tjaalgard MA. Improved cardiac function following hormonal therapy in brain dead pigs: relevance to organ donation. Cryobiology 1987; 24 $1-10$.

26. Novitzky D, Cooper DK, Reichart B. Hemodynamic and metabolic responses to hormonal therapy in brain-dead potential organ donors. Transplantation 1987; 43 852-854

27. Rosendale JD, Kauffman HM, McBride MA, Chabalewski FL, Zaroff JG, Garrity ER, et al Hormonal resuscitation yields more transplanted hearts with improved early function. Transplantation 2003; 75: 1336-1341.

28. Dhar R, Cotton C, Coleman J, Brockmeier D, Kappel D, Marklin G, et al. Comparison of high- and low-dose corticosteroid regimens for organ donor management. J Crit Care 2013; 28: e1-e7.

29. Rebolledo R, Liu B, Akhtar MZ, Ottens PJ, Zhang JN, Ploeg RJ, et al. Prednisolone has a positive effect on the kidney but not on the liver of brain dead rats: a potencial role in complement activation. J Transl Med 2014; 12: 1-10.

30. Schnuelle P, Berger S, de Boer J, Persijn G, van der Woude FJ. Effects of catecholamine application to brain-dead donors on graft survival in solid organ transplantation. Transplantation 2001; 72: 455-463.

31. Yamaoka Y, Taki Y, Gubernatis G, Nakatani T, Okamoto R, Yamamoto Y, et al. Evaluation of the liver graft before procurement. Significance of arterial ketone body ratio in brain-dead patients. Transplant Int 1990; 3: 78-81.

32. Lewis AJ, Rostron AJ, Cork DM, Kirby JA, Dark JH. Norepinephrine and arginine vasopressin increase hepatic but not renal inflammatory activation during hemodynamic resuscitation in a rodent model of brain-dead donors. Exp Clin Transplant 2009; 7: 119-123.

33. Okamoto R, Yamamoto Y, Lin H, Ueda J, Yokoyama T, Tanaka K, et al. Influence of dopamine on the liver assessed by changes in arterial ketone body ratio in brain-dead dogs. Surgery 1990; 107: 36-42.

34. Cooper DK, Novitzky D, Wicomb WN, BAsker M, Rosendale JD, Myron Kauffman H. A review of studies relating to thyroid hormone therapy in brain-dead organ donors. Front Biosci 2009; 14: 3750-3770.

35. Powner DJ, Hernandez M. A review of thyroid hormone administration during adult donor care. Prog Transplant 2005; 15: 202-207.

36. Attia M, Silva MA, Mirza DF. The marginal liver donor - an update. Transpl Int 2008; 21 713-724

37. Cameron AM, Ghobrial RM, Yersiz H, Farmer DG, Lipshutz GS, Gordon SA, et al. Optima utilization of donor grafts with extended criteria: a single-center experience in over 1000 liver transplants. Ann Surg 2006; 243: 748-753.

38. Feng S, Goodrich NP, Bragg-Gresham JL, Dykstra DM, Punch JD, DebRoy MA, et at. Characteristics associated with liver graft failure: the concept of a donor risk index. Am J Transplant 2006; 6: 783-790.

39. Bartlett A, Heaton N. Current challenges and controversies in liver transplantation Eur Gastroenterol Hepatol 2007; 1: 39-41.

40. Berenguer M, Prieto M, San Juan F, Rayón JM, Martinez F, Carrasco D, et al. Contribution of donor age to the recent decrease in patient survival among HCV-infected liver transplant recipients. Hepatology 2002; 36: 202-210.
41. Oh CK, Sanfey HA, Pelletier SJ, Sawyer RG, McCullough CS, Pruett TL. Implication of advanced donor age on the outcome of liver transplantation. Clin Transplant 2000; 14: 386-390.

42. Grazi GL, Cescon M, Ravaioli M, Ercolani G, Pierangeli F, D'Errico A, et al. A revised consideration on the use of very aged donors for liver transplantation. Am J Transplant 2001; 1: $61-68$

43. Busquets J, Xiol X, Figueras J, Jaurrieta E, Torras J, Ramos E, et al. The impact of donor age on liver transplantation: influence of donor age on early liver function and on subsequent patient and graft survival. Transplantation 2001; 71: 1765-1771.

44. Ioannou GN. Development and validation of a model predicting graft survival after liver transplantation. Liver Transp/ 2006; 12: 1594-1606.

45. Jiménez RC, Moreno GE, Colina RF, Palma CF, Loinaz SC, Rodriguez GF, et al. Use of octogenarian livers safely expands the donor pool. Transplantation 1999; 68: 572-575.

46. Wynne HA, Cope LH, Mutch E, Rawlins MD, Woodhouse KW, James OF. The effect of age upon liver volume and apparent liver blood flow in healthy man. Hepatology 1989; 9 : 297-301.

47. D'Alessandro AM, Kalayoglu M, Sollinger HW, Hoffmann RM, Reed A, Knechtle SJ, et al. The predictive value of donor liver biopsies for the development of primary nonfunction after orthotopic liver transplantation. Transplantation 1991; 51: 157-163.

48. Loinaz C, Gonzalez EM. Marginal donors in liver transplantation. Hepatogastroenterology 2000; 47: 256-263

49. Rinella ME, Alonso E, Rao S, Whitington P, Fryer J, Abecassis M, et al. Body mass index as a predictor of hepatic steatosis in living liver donors. Liver Transpl 2001; 7: 409-414.

50. Angelico M. Donor liver steatosis and graft selection for liver transplantation: a short review. Eur Rev Med Pharmacol Sci 2005; 9: 295-297.

51. Chavin KD, Yang S, Lin HZ, Chatham J, Chacko VP, Hoek JB, et al. Obesity induces expression of uncoupling protein-2 in hepatocytes and promotes liver ATP depletion. $J$ Biol Chem 1999; 274: 5692-5700.

52. Verran D, Kusyk T, Painter D, Fischer J, Koorey D, Strasser S, et al. Clinical experience gained from the use of 120 steatotic donor livers for orthotopic liver transplantation. Liver Transplant 2003; 9: 500-505.

53. Imber CJ St, Peter SD, Handa A, Friend PJ. Hepatic steatosis and its relationship to transplantation. Liver Transplant 2002; 8: 415-423.

54. Strasberg SM, Howard TK, Molmenti EP, Hertl M. Selecting the donor liver: risk factors for poor function after orthotopic liver transplantation. Hepatology 1994; 20: 829-838.

55. Urena MA, Moreno Gonzalez E, Romero CJ, Ruiz-Delgado FC, Moreno Sanz C. An approach to the rational use of steatotic donor livers in liver transplantation. Hepatogastroenterology 1999; 46: 1164-1173.

56. Soejima Y, Shimada M, Suehiro T, Kishikawa K, Yoshizumi T, Hashimoto K, et al. Use of steatotic graft in living-donor liver transplantation. Transplantation 2003; 76: 344-348.

57. Koneru B, Dikdan G. Hepatic steatosis and liver transplantation current clinical and experimental perspective. Transplantation 2002; 73: 325-330.

58. Seifalian AM, Chidambaram V, Rolles K, Davidson BR. In vivo demonstration of impaired microcirculation in steatotic human liver grafts. Liver Transpl Surg 1998; 4: 71-77.

59. Onumata O, Takahashi T, Sato K, Kakita A. Effects of ulinastatin on hypotension and hepatic circulation in brain dead rabbits. Transplant Proc 2000; 32: 2290

60. Jiménez-Castro MB, Meroño N, Mendes-Braz M, Gracia-Sancho J, Martínez-Carreres L, Cornide-Petronio ME, et al. The effect of brain death in rat steatotic and non-steatotic liver transplantation with previous ischemic preconditioning. J Hepatol 2015; 62: 83-91.

61. Zamir G, Olthoff KM, Desai N, Markmann JF, Shaked A. Toward further expansion of the organ pool for adult liver recipients: splitting the cadaveric liver into right and left lobes. Transplantation 2002; 74: 1757-1761.

62. Humar A, Ramcharan T, Sielaff TD, Kandaswamy R, Gruessner RW, Lake JR, et al. Split liver transplantation for two adult recipients: an initial experience. Am J Transplant 2001; 1: 366-372.

63. Azoulay D, Castaing D, Adam R, Savier E, Delvart V, Karam V, et al. Split-liver transplantation for two adult recipients: feasibility and long-term outcomes. Ann Surg 2001; 233: $565-574$.

64. Liu C, Fan ST. Adult-to-adult live-donor liver transplantation: The current status. $J$ Hepatobiliary Pancreat Surg 2006; 13: 110-116.

65. Oswari H, Lynch SV, Fawcett J, Strong RW, Ee LC. Outcomes of split versus reduced-size grafts in pediatric liver transplantation. J Gastroenterol Hepatol 2005; 20 $1850-1854$

66. Wojcicki M, Silva MA, Jethwa P, Gunson B, Bramhall SR, Mayer D, et al. Biliary complications following adult right lobe ex vivo split liver transplantation. Liver Transp/ 2006; 12: 839-844

67. Saab S, Chang AJ, Comulada S, Geevarghese SK, Anselmo RD, Durazo F, et al. Outcomes of hepatitis $\mathrm{C}$ - and hepatitis $\mathrm{B}$ core antibody-positive grafts in orthotopic liver transplantation. Liver Transpl 2003; 9: 1053-1061.

68. Penn I. Transmission of cancer from organ donors. Ann Transplant 1997; 2: 7-12.

69. Kauffman HM, McBride MA, Cherikh WS, Spain PC, Delmonico FL. Transplant tumor registry: donors with central nervous system tumors. Transplantation 2002; 73: 579-582. 
70. Buell JF, Beebe TM, Trofe J, Gross TG, Alloway RR, Hanaway MJ, et al. Donor transmitted malignancies. Ann Transplant 2004; 9: 53-56.

71. Mukherjee S, Sorrell MF. Controversies in liver transplantation for hepatitis C. Gastroenterology 2008; 134: 1777-1788.

(c) (i)

Cell Death and Disease is an open-access journal published by Nature Publishing Group. This work is licensed under a Creative Commons Attribution 4.0 International License. The images or other third party material in this article are included in the article's Creative Commons license, unless indicated otherwise in the credit line; if the material is not included under the Creative Commons license, users will need to obtain permission from the license holder to reproduce the material. To view a copy of this license, visit http://creativecommons.org/licenses/by/4.0/ 